(2) Open Access Full Text Article

ORIGINALRESEARCH

\title{
latrogenic Ureteral Injuries Associated with Gynecological and Surgical Procedures: Our Experience About 18 Cases and Literature Review
}

\author{
Adama Ouattara $\mathbb{D}^{\prime}$ \\ Abdoul-Karim Pare' \\ Fasnewinde Aristide Kabore $\mathbb{I D}^{2}$ \\ Clotaire Yameogo ${ }^{2}$ \\ Desire Ky ${ }^{2}$ \\ Dramane Bayané \\ Delphine $\mathrm{Ye}^{\mathrm{I}}$ \\ Timothee Kambou' \\ 'Division of Urology, Souro Sanou \\ Teaching Hospital, Bobo-Dioulasso, \\ Burkina Faso; ${ }^{2}$ Division of Urology, \\ Yalgado Ouedraogo Teaching Hospital, \\ Ouagadougou, Burkina Faso
}

\begin{abstract}
Aim: To describe the epidemiological aspects, etiology and outcome of iatrogenic ureteral injury repair at the urology division of Souro Teaching Hospital of Bobo Dioulasso (BurkinaFaso).

Patients and Methods: This was a retrospective descriptive study of consecutive patients with iatrogenic ureteric injuries who were referred and managed in the urology division of Souro Sanou Teaching Hospital (Bobo-Dioulasso) from January 2012 to December 2017. Variables studied were age, the time at the diagnosis, the causative event, the method of repair, and the outcome of the management.
\end{abstract}

Results: The mean age was $37.72 \pm 3.5$ years coming from the rural population in most cases. The mean time at the diagnosis was 15 days. The injuries were due to gynecologic surgeries with hysterectomy $(66 \%)$ and caesarian section $(33 \%)$. Ureteric reimplantation with antireflux system was performed in seventeen patients. The rate of treatment success was $94 \%$ and the postoperative course was uneventful for all the patients.

Conclusion: Iatrogenic ureteric lesions at the department of urology of Sanou Sourou teaching hospital of Bobo Dioulasso were mainly caused by gynecologic and obstetric surgeries like hysterectomy and caesarian section.

Keywords: iatrogenic, ureter, injury, pelvic surgery

\section{Introduction}

Pelvic surgery is relatively difficult due to the richness and the particularity of this anatomic region in terms of neurovascular and visceral organs. ${ }^{1}$ Iatrogenic ureteral injury is a potential complication of all surgical procedures performed in the pelvis. ${ }^{2}$ It occurs mainly during female pelvic surgery and can result in devastating consequences and even mortality in the short-term and potential loss of organ function in the long-term. ${ }^{3}$ Theses lesions are generally managed by urologists and sometimes in association with gynecologists. ${ }^{4}$ The close anatomical relationships between the urinary and genital tracts in women was the main risk factor of iatrogenic injuries during surgical procedures. In addition, poor knowledge of anatomy of the pelvic area by surgeon and his qualification, anatomical variations, surgical bleeding, obesity, malignant tumor surgeries and presence of adhesions in pelvic are also risk factors that can lead to inadvertent damage of the ureter. ${ }^{5}$ Frequency, clinical and therapeutical characteristics of
Correspondence: Adama Ouattara Division of Urology, P.O. Box:|465, Bobo-Dioulasso, Burkina-Faso

Email adamsouat I@hotmail.com 


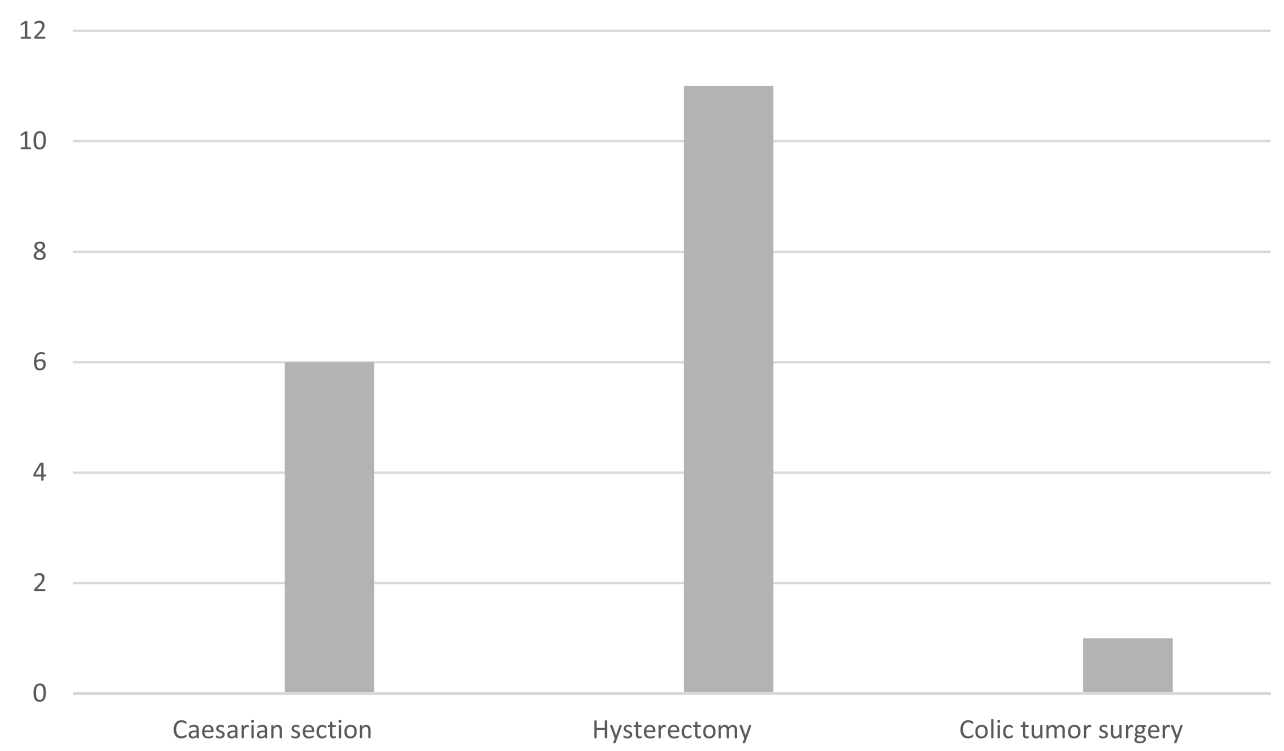

Figure I Distribution of patients according to the causative event.

iatrogenic ureteral injuries are not well described in our setting and no previous reports are available on the occurrence of such complications in our context. The aim of this study was to describe the epidemiological, anatomic and therapeutical aspects of iatrogenic ureteral injuries during pelvic surgery in Souro Sanou University Teaching Hospital.

\section{Patients and Methods}

This was a retrospective descriptive study concerning all the patients with iatrogenic ureteric injuries managed in the context of emergency or scheduled surgery in the urology division of Souro Sanou Teaching Hospital of Bobo Dioulasso from January 2012 to December 2017. We included the cases of ureteral injuries in which information about clinical observation, imaging (abdominopelvic ultrasound, intravenous urography, or CT scan) and operative report were available. Variables studied were age, the timing of diagnosis, the causative event, the method of repair of the lesions and the outcome of repair. The data were analyzed using Epi Info software

Table I Distribution of Patients According to the Side of the Lesion

\begin{tabular}{|l|c|c|}
\hline Ureteral Injury & Frequency & Percentage (\%) \\
\hline Left side & 13 & 72.22 \\
Right side & 4 & 22.22 \\
Bilateral & 1 & 5.56 \\
Total & 18 & 100 \\
\hline
\end{tabular}

version 7. The qualitative variables were expressed in terms of proportion while quantitative variables consisted of measuring the mean with $\mathrm{SD}$, median and ranges. Ethics approval was granted by the Ethics Committee of the Department of Surgery, University Teaching Hospital Souro Sanou. Previously admitted to the hospital, all the patient were informed and consented to review their medical records, and their names and identities were protected and anonymous.

\section{Results}

During the study period of six years, 18 patients were managed for iatrogenic ureteric injuries in the division of urology of Souro Sanou Teaching Hospital of Bobo Dioulasso, giving a frequency of three cases per year.

The mean age of the patients was $37.72 \pm 3.5$ years. Most of the patients were housewives $(88.88 \%)$, out-ofschool (83.33\%) and were from rural areas $(66.7 \%)$.

According to the mode of admission, only one third (1/3) of the patients were admitted in the operating room in a context of emergency, in contrast to two thirds of them who were referred from a primary or rural medical center for better management. The mean time between the patient referral and the surgery was 15 days ranging from $24 \mathrm{~h}$ to six months (180 days).

The modes of the presentation were leakage of urine in peritoneum (1), anuria or oliguria after surgery (3), flank or lumbar pain (4), urinary leakage from vagina (3), and six patients did not have complaints. The ureter injuries were diagnosed after intravenous urography (IVU). 


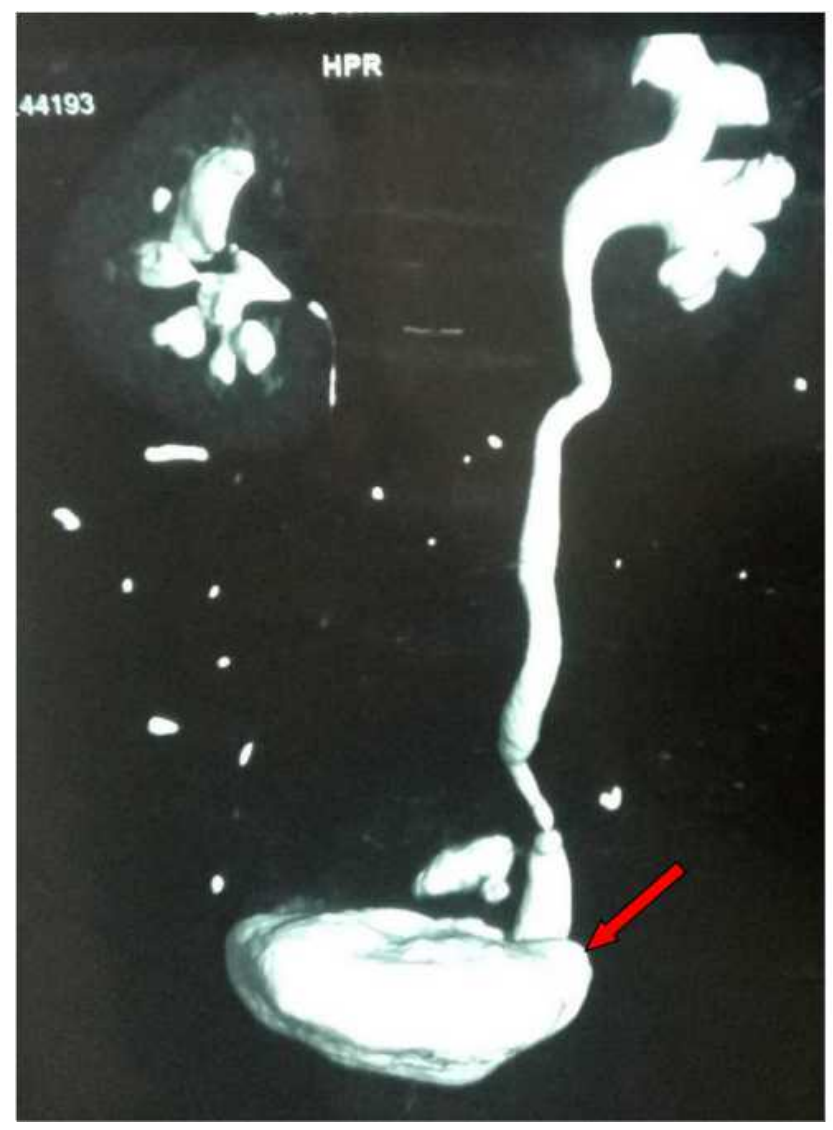

Figure 2 Reconstruction CT scan: posthysterectomy left ureterohydronephrosis with pelvic ureter injury (red arrow).

Among the causative events, hysterectomy was the first procedure which provides iatrogenic ureteral injury (Figure 1). All the hysterectomy procedures were performed by abdominal route. In one patient the lesion was recognized operatively during the surgery. It was a section of the pelvic portion of right ureter and ureterostomy was performed timely before her reference to the urology division of Souro Sanou Teaching Hospital for appropriate surgical management by an urologist.

The type of ureteral injury was respectively, suture in $50 \%$ of patients, partial ligation in $25 \%$ of patients and complete ureteric transection in $25 \%$.

According to the laterality, the left pelvic ureter was most injured compared to the right one (Table 1).

Intravenous urography (IVU) or CT scan were performed in six patients and all of them had pelvicalyceal dilatation or ureterohydronephrosis at diagnosis (Figure 2).

About the management, 17 patients had benefited from ureteric reimplantation with antireflux system. One patient was managed by $\mathrm{JJ}$ stent placement. The cure of ureterovaginal fistula was performed in a second patient.
The follow-up was uneventful and 17 patients were totally cured without any postoperative complications.

\section{Discussion}

During the study period of six years, 18 cases of iatrogenic ureteral injury were recorded, giving a frequency of three cases per year. Frequency of 3.5 cases per year was reported by El Abd in Egypt during 28 years., Although iatrogenic ureteric injury is relatively uncommon, it is a serious event occurring during surgery with a real medicolegal implication. ${ }^{7,8}$

The mean age was 37.72 years. Kirakoya et al in Ouagadougou, Bouya et al in Brazzaville and Kpatcha et al in Dakar reported a mean age of 36.4 years, 37 years and 34.2 years in their respective series. ${ }^{9-11}$ In fact, it is during the premenopausal period, during their thirties that most women underwent hysterectomy for benign diseases like fibroma or uterine prolapse; thus increasing their risk of ureteric injury. ${ }^{12}$ The mean timing of diagnosis was 15 days ranging from 1 to 180 days. An early diagnosis of ureteral injury is difficult despite an intraoperative assessment of hematuria or cystoscopy. ${ }^{13}$ However, hematuria is typically absent on initial presentation. Symptoms of a late diagnosis are usually nonspecific and include prolonged ileus, urinary leakage, prolonged high output from drains, fever/sepsis, persistent flank or abdominal pain, urinary obstruction, elevated creatinine or blood urea nitrogen, and flank mass. ${ }^{14}$ As delayed diagnosis and consequently delayed management results in higher complications including infection, urinoma, ureteric stricture, urinary fistula, and renal loss, surgeons had to be aware of this lesion for early recognition.

In our study, gynecologic surgery was the causative event of the ureter postoperative injuries (95\%). A past review has confirmed the superiority of gynecologic surgery as a cause of iatrogenic ureteral injury. ${ }^{15}$ In contrast to that reported by Olatunji et al in Nigeria where caesarian delivery was the leading gynecologic surgery, in our study, hysterectomy was reported in $61 \%$ Globally, iatrogenic ureteric trauma is the common cause of ureteral injury with gynecologic surgery being the most causative event. ${ }^{16}$

According to the laterality, the lesion was unilateral in $95 \%$ with the left ureter $72 \%$ of cases. In the study of Chalya et al in Tanzania, the left side was also reported in $70 \%$ of cases. ${ }^{17}$ The left ureter is much more at risk, and most prior series reveal iatrogenic ureteral injury on the left three to five times more often than on the right side. This increased risk 
to the left ureter is related to its course, which places it much closer to the cervix than the right ureter. ${ }^{18}$

Bilateral ureteral injury was reported in one case. The 30year-old patient underwent vaginal hysterectomy for pelvic organ prolapse and secondary referral to our emergency unit for postoperative anuria. Diallo et al did not report any case of bilateral ureteral injury. ${ }^{19}$ It is evident that a bilateral lesion shared a double risk for the patient, including genito-urinary fistulae and may influence the outcome of the management. $^{20-22}$

According to the therapeutic aspects, all of our patients underwent open surgery with uretero-vesical reimplantation except one of who was managed by JJ stent placement with a total success rate of $94 \%$. No complication was observed in our serie.s Goodwin and Scardino had a success rate of $100 \%$ for the 16 patients in their series treated with ureteroneocystostomy. ${ }^{23}$ Beland found that reimplantation of the ureter with an anti-refluxing technique is preferable. ${ }^{24}$ Ureterovesical reimplantation is a complex but well known and codified intervention with good functional results and lower morbidity when done by an experienced surgeon.

\section{Conclusion}

Iatrogenic ureteral injuries in our urology division were mainly due to gyneco-obstetric surgery, especially hysterectomy and caesarean delivery. They are related to the pathological context often resulting in anatomical changes on the one hand and the lack of experience of some surgeons on the other hand. A close collaboration and partnership between urologists and gynecologists, therefore, appears to be essential in our setting in order to optimize the management of these adverse events, which are not devoid of subsequent consequences.

\section{Funding}

There is no funding to report.

\section{Disclosure}

The authors report no conflicts of interest in this work.

\section{References}

1. Corton MM. Anatomy of pelvic floor dysfunction. Obstet Gynecol Clin North Am. 2009;36(3):401-419. doi:10.1016/j.ogc.2009.09.002

2. O'Connor EM, Greenwell TJ. Urological complications following gynaecological surgery. Obstet Gynaecol Reprod Med. 2018. doi:10.1016/j.ogrm.2018.12.002

3. Burks FN, Santucci RA. Management of iatrogenic ureteral injury. Ther Adv Urol. 2014;6(3):115-124. doi:10.1177/1756287214526767
4. De Cicco C, Ret Davalos ML, Van Cleynenbreugel B, Verguts J, Koninckx PR. Iatrogenic ureteral lesions and repair: a review for gynecologists. J Minim Invasive Gynecol. 2007;14(4):428-435. doi:10.1016/j.jmig.2007.01.003

5. Elawdy MM, Osman Y, Awad B, El-Mekresh M, El-Halwagy S. Iatrogenic ureteral injuries: a case series analysis with an emphasis on the predictors of late ureteral strictures and unfavorable outcome in different surgical specialties. Int Urogynecol J. 2020;11:1-6.

6. El Abd AS, El-Abd SA, El-Enen MA, et al. Immediate and late management of iatrogenic ureteric injuries: 28 years of experience. Arab J Urol. 2015;13:250-257. doi:10.1016/j.aju.2015.07.004

7. Gild P, Kluth LA, Vetterlein MW, Engel O, Chun FKH, Fisch M. Adult iatrogenic ureteral injury and stricture incidence and treatment strategies. Asian J Urol. 2018;5(2):101-106. doi:10.1016/j. ajur.2018.02.003

8. Sallami S. Iatrogenic ureteric injury: a real medicolegal dilemma. Tunis Med. 2012;90(11):819-823.

9. Kirakoya B, Yaméogo CAMKD, Paré AK, Kaboré M, Kaboré FA, Zango B. Ureteral injuries during gynecologic and obstetric procedures. Uro'Andro. 2018;1(9):419-423.

10. Bouya PA, Odzébé AWS, Otiobanda FG, et al. Urologic complications of gynecologic surgery. Prog Urol. 2011;21(12):875-8. doi:10.1016/j.purol.2011.03.008

11. Kpatcha TM, Tengué K, Anoukoum T, et al. Urologic complications during pelvic surgery in Aristide Le Dantec teaching hospital in Dakar. Afr J Urol. 2014;20(4):206-10. doi:10.1016/j. afju.2014.04.007

12. Deffieux X, de Rochambeau B, Chene G, Gauthier T. Hysterectomy for benign disease: clinical practice guidelines from the French College of Obstetrics and Gynecology. Eur $J$ Obstet Gynecol Reprod Biol. 2016;202:83-91. doi:10.1016/j.ejogrb.2016.04.006

13. Gilmour DT, Das S, Flowerdew G. Rates of urinary tract injury from gynecologic surgery and the role of intraoperative cystoscopy. Obstet Gynecol. 2006;107(6):1366-1372. doi:10.1097/01.AOG.0000220500.83528.6e

14. Brabes S, Coburin M, Armenakas N, Mc Annich J. Diagnosis and management of ureteric injury: an evidence-based analysis. BJU Int. 2004;94(3):277-289. doi:10.1111/j.1464-410X.2004.04978.x

15. Klap J, Phé V, Chartier-Kastler E, et al. Aetiology and management of iatrogenic injury of the ureter: a review. Prog Urol. 2012;22 (15):913-9.

16. Olatunji L, Olunwasomidoyin B, Morhason-Bello I, Abdus-salam R, Ojengbede O. Our experience with iatrogenic ureteric injuries among women presenting to University College Hospital, Ibadan: a call to action on trigger factors. Obstet Gynecol Int. 2019. doi:10.1155/2019/ 6456141

17. Chalya PL, Massinde AN, Kihunrwa A, Simbila S. Iatrogenic ureteric injuries following abdominopelvic operations: a 10-year tertiary care hospital experience in Tanzania. World J Emerg Surg. 2015;10:17. doi:10.1186/s13017-015-0011-Z

18. Meirow D, Moriel EZ, Zilberman M, Farkas A. Evaluation and treatment of iatrogenic ureteral injuries during obstetric and gynecologic operations for nonmalignant conditions. J Am Coll Surg. 1994;178(2):144.

19. Diallo M, Diallo A, Sow K, Guirassy S, Diallo I. Urological complications of gynecological surgery: sixteen cases report. Ann Urol. 2001;35(4):210-5.

20. Sanda G, Chipkao R, Harissou A, Soumana A, Tassiou EM. Iatrogenic genito-urinary fistulae: a report of 62 cases and literature review. Afr J Urol. 2016;22(2):55-60.

21. Gambachidze D, Phé V, Drouin SJ, et al. Functional outcomes obtained after vesicoureteral reimplantation surgery in adults: a review. Prog Urol. 2015;25(12):683-691. doi:10.1016/j. purol.2015.06.007

22. Chapple CR, Png JC. Principles of ureteric reconstruction. Curr Opin Urol. 2000;10(3):207-212. doi:10.1097/00042307-200005000-00004 
23. Goodwin WE, Scardino PT. Vesicovaginal and ureterovaginal fi stulas: a summary of 25 years of experience. J Urol. 1980;123 (3):370. doi:10.1016/S0022-5347(17)55941-8
24. Beland G. Early treatment of ureteral injuries found after gynecological injury. J Urol. 1977;118(1 Part 1):25. doi:10.1016/S00225347(17)57874-X

\section{Publish your work in this journal}

Research and Reports in Urology is an international, peer-reviewed, open access journal publishing original research, reports, editorials, reviews and commentaries on all aspects of adult and pediatric urology in the clinic and laboratory including the following topics: Pathology, pathophysiology of urological disease; Investigation and treatment of urological disease; Pharmacology of drugs used for the treatment of urological disease. The manuscript management system is completely online and includes a very quick and fair peer-review system, which is all easy to use. Visit http://www.dovepress.com/ testimonials.php to read real quotes from published authors. 